\title{
Zika Virus Overview: Transmission, Origin, Pathogenesis, Animal Model and Diagnosis
}

\author{
Dallas Vue and Qiyi Tang*
}

\begin{abstract}
Zika virus (ZIKV) was first discovered in 1947 in Uganda. ZIKV did not receive substantial attention until Brazil hosted the 2016 Summer Olympic Games, and ZIKV reached a global audience. ZIKV is a flavivirus transmitted chiefly through mosquito bites, sexual intercourse and, to a lesser extent, breastfeeding. The recent discovery of how ZIKV causes congenital neurodevelopmental defects, including microcephaly, has led to reevaluation of the importance of the interaction of ZIKV with centrosome organization, because centrosomes play an important role in cell division. When ZIKV disrupts centrosome organization and mitotic abnormalities, neural progenitor differentiation is altered, thereby resulting in cell cycle arrest, increased apoptosis and inhibition of neural progenitor cell differentiation; subsequently, abnormalities in neural cell development can result in microcephaly. To aid in the understanding of the importance of ZIKV infection, this review article provides an overview of its history, transmission routes, pathogenesis, animal models and diagnosis.
\end{abstract}

Key words: Zika virus (ZIKV) centrosome, flavivirus, microcephaly
Edited by:

Hua Li, Huazhong University of Science and Technology, Tongji Medical College, China

Reviewed by:

Zhu, Hua, Rutgers New Jersey

Medical School, USA

The other two reviewers requested to be anonymous.

*Corresponding author:

E-mail: qiyi.tang@howard.edu

Department of Microbiology, Howard University College of Medicine, 520 W Street NW Washington, DC 20059, USA

Received: October 32021

Revised: November 122021

Accepted: November 162021

Published Online: December 72021

\section{BACKGROUND}

Zika virus (ZIKV), along with yellow fever, Japanese encephalitis, West Nile virus and dengue virus, is characterized as a positive-sense single-stranded RNA virus of the family Flaviviridae and the genus flavivirus. An in-depth summary of the family Flaviviridae, which includes many other viruses, has been provided in a 2010 review [1]. ZIKV can be classified into distinct African and Asian lineages through phylogenetic analysis; both lines emerged from East Africa during the late 1800s or early 1900s [2]. The Asian line originated during the virus's migration from Africa to Southeast Asia, and was first detected in Malaysia [2]. ZIKV is a mosquito-borne flavivirus typically causing mild illness; its scope has rapidly expanded worldwide, causing maternal infection and fetal viral transmission [3]. Examination of ZIKV's effects on the health of newborns is crucial for understanding how viral infections affect cellular physiology [4]. ZIKV is associated with microcephaly in newborns whose mothers were infected with ZIKV. Viral microcephaly is a congenital disability wherein the baby's head is smaller than normal according to sex and age [5]. Babies with microcephaly often have smaller brains that hinder their development with respect to that of their peers, thus resulting in a range of health problems [5].

The mechanisms through which ZIKV causes microcephaly have been investigated in detail. Most experimental results support the hypothesis that ZIKV infects neural progenitor cells (NPCs) of the fetal brain and results in microcephaly [6]. 
Animal models have shown that ZIKV infection causes cell cycle arrest, apoptosis of NPCs, massive neuronal death and axonal rarefaction [7-9]. The human neural organoid model has also shown that ZIKV infection increases cell death and decreases proliferation, thus decreasing neuronal cell-layer volume in a manner resembling microcephaly, although the mechanisms of the biological effects may differ [10-12]. Our studies have demonstrated that ZIKV affects centrosomes and consequently newborn development, because centrosomes play a crucial role in cell division [13]. Therefore, ZIKV causes defects in fetal brain development and microcephaly through multiple mechanisms. However, fewer than $5 \%$ of congenitally infected newborns develop microcephaly, whereas more than $95 \%$ of congenitally infected cases are normal at birth $[4,14,15]$. Therefore, the factors involved in ZIKV-associated microcephaly remain to be revealed. This review summarizes five aspects of ZIKV: transmission, origin, pathogenesis, animal models and diagnosis. The future of ZIKV studies is also discussed.

\section{TRANSMISSION OF ZIKV}

\section{Mosquito biting}

ZIKV is closely related to Spondweni virus, according to phylogenetic analysis, and both are mosquito-borne viruses capable of causing human disease [16]. Arboviruses generally describe hundreds of RNA viruses relying on arthropods, such as mosquitoes or ticks, to transmit infection to humans through biting [17]. Like many other flaviviruses, ZIKV is transmitted in humans through bites by infected mosquitoes, mainly Aedes aegypti, predominantly the Aedes (Stegomyia) genus [18-20]. Aedes aegypti mosquitoes usually bite during the day, and their activity peaks during the early morning and late afternoon/evening in tropical and subtropical regions [18-20]. In studies examining ZIKV transmission through infected mosquitoes, ZIKV has been isolated in the two known ZIKV-lineage regions of Africa and Asia from several different mosquito species in the Aedes genus (e.g., A. aegypti, $A$. africanus, $A$. albopictus, $A$. apicoargenteus, $A$. furcifer, $A$. luteocephalus, $A$. opok and $A$. vittatus); these species may potentially act as vectors for viral transmission in those endemic areas [21-30].

Aedes aegypti primarily transmits the four viruses that have had the greatest effects on human health: yellow fever virus, dengue fever, chikungunya and ZIKV. As shown in Fig 1, mosquitoes require 5-8 days to develop from eggs via larvae to pupae, and another 3 days to become adults [31]. If an adult mosquito bites a ZIKV-carrying primate, the mosquito is likely to acquire the virus from the animal's blood. Then ZIKV infects and replicates in the epithelial cells of the mosquito, circulates in its blood and is released in its saliva. Infectious mosquitoes transmit ZIKV to other non-human primates (NHPs) or to humans. Mosquito transmission expands the infected populations, and subsequently causes outbreaks or epidemics. During epidemics, ZIKV transmission may occur via sexual activity, and to a lesser extent breast milk feeding and vertical transmission.

\section{Sexual transmission}

The first reported case of a sexually transmitted ZIKV infection occurred in Colorado, USA, in 2008 [32]. A female patient who did not have a travel history to any ZIKV-endemic region experienced ZIKV-like symptoms [32]. Her husband was an American scientist who had contracted ZIKV infection through frequent bites from wild Aedes spp. mosquitoes in the evenings, while he conducted a routine mosquito-sampling project in villages in Senegal in 2008 [33]. After the infected American scientist returned home from Senegal, the couple had vaginal sexual intercourse, which provided a direct-contact transmission route for a likely sexually transmitted infection [33]. Subsequently, many more sexually acquired ZIKV cases were reported in non-endemic regions. Infected partners often returned from endemic areas and had sexual intercourse, thus increasing ZIKV cases [34]. Public health findings suggested that sexual transmission might have been responsible for the rapid spread of ZIKV, which expanded to various geographical regions and to healthy people worldwide, with unclear effects on fertility and the safety of sperm and egg banks [35]. Therefore, in 2017, the World Health Organization (WHO) constructed a plan to understand ZIKV sexual transmission and determine how to combat the ZIKV epidemic [36]. Notably, ZIKV infects the testis and is present in seminal fluid; to our knowledge, sexual transmission can occur from males to females [32]. Interestingly, sexual transmission has never been observed in any other mosquitoborne flavivirus.

\section{Breastfeeding}

ZIKV transmission from mother to child has been shown to cause harm to children during pregnancy or birth; however, less is known regarding transmission through breast milk, given the limited data and publications available [37]. According to the Centers for Disease Control and Prevention $[38,39]$, breastfeeding is an investment in health that generally helps decrease disease risks for infants and mothers. Because of the limited data available regarding the potential risk that human milk might transmit ZIKV, the WHO made a collective decision that the benefits of breastfeeding for the infant and mother outweigh the potential risk of ZIKV transmission. This conclusion was supported by an animal study demonstrating that suckling mice can be infected with ZIKV through ingestion of ZIKV-containing human milk, but human breast milk has potential antiviral activity [40]. Even though ZIKV transmission through breast milk might be possible, the WHO still recommended that mothers with suspected or confirmed ZIKV infection continue to breastfeed their children [41,42]. Fig 1 shows the vertical transmission, sexual transmission and breastfeeding transmission of ZIKV.

\section{ORIGIN OF ZIKV LINEAGES}

\section{African lineage of ZIKV}

ZIKV was first identified in 1947 in the Zika forest in Uganda by British scientists working in the Yellow Fever 


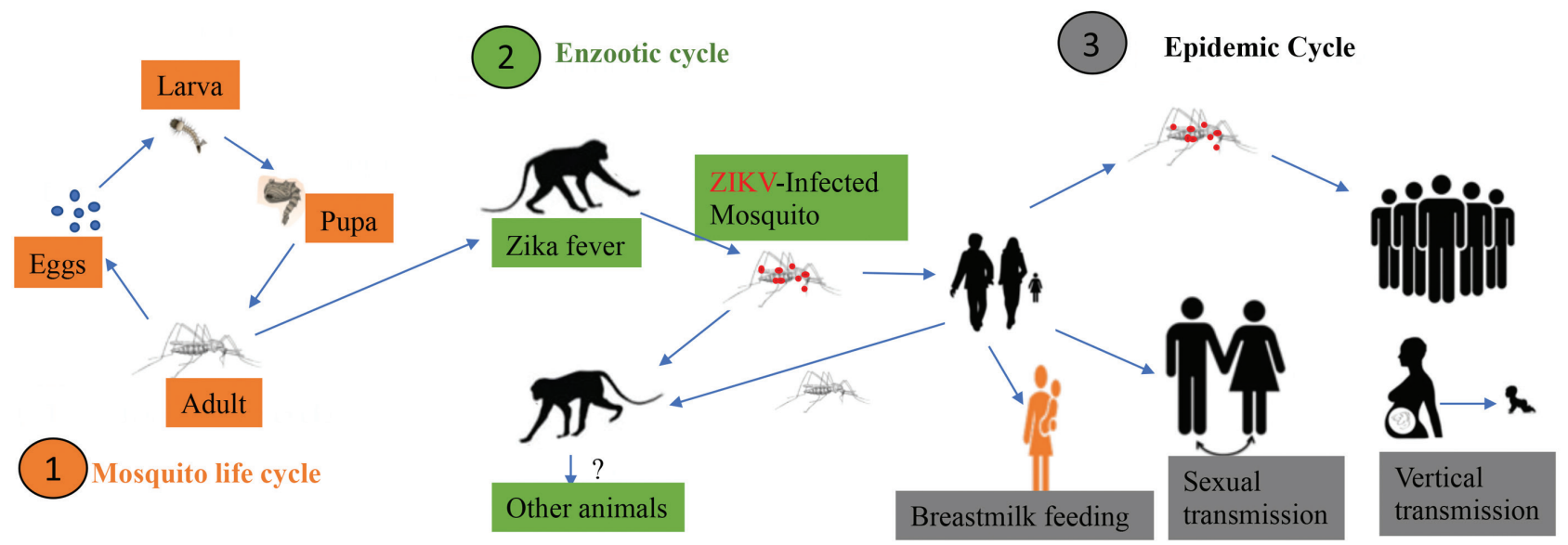

FIGURE 1 | 1. The life cycle of a mosquito. 2. ZIKV infection and transmission from NHPs to other NHPs or humans. 3. Different modes of ZIKV transmission during epidemics.

Research Laboratory, where ZIKV was isolated from a sentinel rhesus monkey [16,21]. Dick et al. [21], on April 18, 1947 , placed a rhesus monkey in a cage on a tree platform in the Zika Forest and observed that the monkey developed a fever. The monkey was a species of Rhesus, and the number given to the rhesus monkey by the Rockefeller Foundation's program for research on jungle yellow fever was 766 [43]. After 2 days, Rhesus 766 still showed fever symptoms and was brought into the Foundation's laboratory in Entebbe, Uganda. Its serum was collected and injected into the brains of mice [43]. After 10 days, all mice with cerebellar exposure to the serum had become sick. Dick et al. then isolated the virus from the mouse brains and named it ZIKV; the strain was MR766 [43]. Thus, the first isolated African strain of ZIKV was named MR766 [44]. The British scientists were studying jungle yellow fever when they identified the ZIKV African lineage.

The first known isolation of ZIKV from humans was reported in 1954 [16]. A 10-year-old Nigerian girl presented at a rural dispensary with a complaint of fever and headache [16]. Because scientists were investigating an outbreak of jaundice in the Afikpo Division, Eastern Nigeria, that they suspected of being yellow fever, they assessed whether the girl had yellow fever [16]. The patient's serum was injected into adult Swiss mice, and several days later, ZIKV was isolated from the mice [16]. Two other cases of ZIKV infection were reported in Nigeria in 1954: the first was in a 30-year-old Nigerian man, and the second was in a 24-year-old Nigerian man. Both cases were confirmed to have ZIKV, on the basis of elevated serum neutralizing antibodies [16]. In summary, the results of these investigations of yellow fever contributed to the finding that ZIKV is an arbovirus, which can be transmitted by mosquitoes and infect at least monkeys and humans.

\section{Asian lineage of ZIKV}

Outside Africa, the first prototype strain of the Asian lineage of ZIKV was isolated in 1966 from mosquito (Aedes aegypti) pools collected in Bentong, Malaysia [29]. Sequence analysis indicated that this Asian lineage of ZIKV was distinct from the original ZIKV; the Asian lineage of ZIKV is considered part of the African lineage [45]. In Asia, between 1954 and 1976, there were no records of human clinical ZIKV cases according to serological tests or viral isolation procedures [46]. ZIKV cases probably remained undetected because ZIKV remained below the limit for clinical detection [46]. In addition, routine checkups were not conducted in which diagnostic tests for ZIKV could be performed [46].

In 1977, 11 years later, a serological study reported that a ZIKV outbreak in Asia occurred in central Java, Indonesia [47]. These reports of ZIKV infection began to occur in the latter half of the rainy season that year, when Aedes aegypti usually flourishes. Seven patients were hospitalized in Tegalyoso Hospital, Klaten, in central Java; each had high fever, malaise, stomachache, dizziness and anorexia [47]. The data from these seven patients indicated that the clinical characteristics of ZIKV infection are usually mild and non-fatal [47]. ZIKV is highly likely to be transmitted by Aedes aegypti, which is a known possible vector in Malaysia [29].

Both the African and Asian ZIKV lineages are related and can be distinguished through detailed analysis of the genomic RNA sequence [45]. The primary difference between strains is the number of available potential glycosylation sites [17]. The distribution area of ZIKV increased to include French Polynesia (FP), given that Zika fever was an emerging infectious disease [48]. As of October 2013 , in FP, a total of 8,700 suspected and 400 laboratoryconfirmed cases had been reported [48]. The complete coding sequence of the virus was obtained from a 51-year-old woman in November 2013 [48]. After returning from FP, she was hospitalized in metropolitan France because she was feeling ill with fever, headache, myalgia, arthralgia and a rash [48]. Coding sequence analysis revealed that the patient had been infected with the ZIKV Asian lineage, which had approximately $99.9 \%$ nucleotide and amino acid sequence identity with the strain that spread during the 2000s in South Asia and the Pacific Islands [17]. These findings 
suggested the existence of a second lineage of ZIKV: the origin of the ZIKV lineage from Uganda probably spread to Malaysia around 1945 and subsequently continued to spread and reached Micronesia around 1960, thereby forming the Asian cluster $[45,49]$. Therefore, two known lineages of ZIKV exist: an African lineage and an Asian lineage [50]. The African lineage is ancestral to the Asian lineage, and both share similar amino acid sequences.

The data overlaid on a world map suggest that distinct modes of ZIKV transmission among humans, animals and mosquitoes have occurred throughout the tropical and subtropical regions of Africa and Asia for more than 70 years. The timeline of events in ZIKV history is summarized in Fig 2.

\section{PATHOGENESIS OF ZIKV}

\section{ZIKV infection of permissive cells}

Little information is available regarding ZIKV pathogenesis, as research is ongoing; however, understanding the life cycle of ZIKV development will aid in the understanding of ZIKV pathogenesis. As described earlier in the section on ZIKV transmission through bites from infected mosquitoes, the primary mosquito vector is Aedes aegypti, predominantly the Aedes (Stegomyia) genus. Aedes mosquitoes lay eggs in high-moisture areas; the eggs then grow from larvae to pupae and finally become adults [Fig 1 and [51]]. The cycle is completed in approximately 1.5-3 weeks [51]. A female adult mosquito can produce a massive quantity (average of 100-200 eggs per batch) after consuming a blood meal, and produces an average of five batches of eggs in her lifetime [51]. Each female produces a total of 500-1,000 eggs in her lifetime. Adult female mosquitoes usually bite humans and animals to obtain blood to enable egg development. As the sylvatic cycle transitions into the urban cycle, humans are affected, because Aedes mosquitoes must bite humans to obtain blood [51].

Aedes mosquitoes infected with ZIKV pierce through the human skin, and the infected mosquito's saliva lubricates the skin and directly contacts human blood. The surface of ZIKV has envelope proteins, which are primarily involved in attachment to host cell membranes as the virus is internalized through endocytosis [51]. As shown in Fig 3, the attachment depends on the interaction between the viral envelope protein and a receptor. AXL, Tyro3, TIM1 and DC-sign have been identified as receptors allowing ZIKV to infect permissive cells $[52,53]$. However, further investigation is necessary, because recent results have been disputed $[54,55]$. Viral entry is completed through endocytosis via endosomes. As the capsid breaks apart in the cytoplasm, viral RNA is released into the endoplasmic reticulum [51]. The positive-sense RNA genome is translated by host ribosomes attached to the endoplasmic reticulum, and structural and non-structural polyproteins are processed through proteolytic activity [51]. When all their parts are assembled correctly, virions are transported out of cells via endosomal sorting complexes, moving from the endoplasmic reticulum-Golgi intermediate compartment to the Golgi apparatus [51]. Through exocytosis, mature virions exit the cell, and a single ZIKV can rapidly yield amounts of virus that can take over the host immune defense system [51].

\section{ZIKV and microcephaly}

In September 2015, multiple reports indicated an increase in the numbers of neonatal microcephaly cases among pregnant women giving birth in northeastern Brazil $[56,57]$.

\section{Zika virus from 1947 to 2017}

1. 1947: Zika virus was
first discovered in
Uganda.
2. 1948: The virus is
recovered from the
mosquito Aedes
africians in Tanzania.
3. 1954: Presence of
Zika virus in Indian
subcontinent.
4. 1954: Nigeria first
human infection of Zika
virus is reported.
5. 1966: Virus was
isolated from Aedes
aegypti obtained from
Malaysia.
6. 1975: Zika virus
made its way into
Gabon.
7. 1997: Zika virus
expands to India,
Pakistan, and Egypt
where the viral
antibodies were
detected from people.
Zika virus makes its
way into Indonesia and
Malaysia.

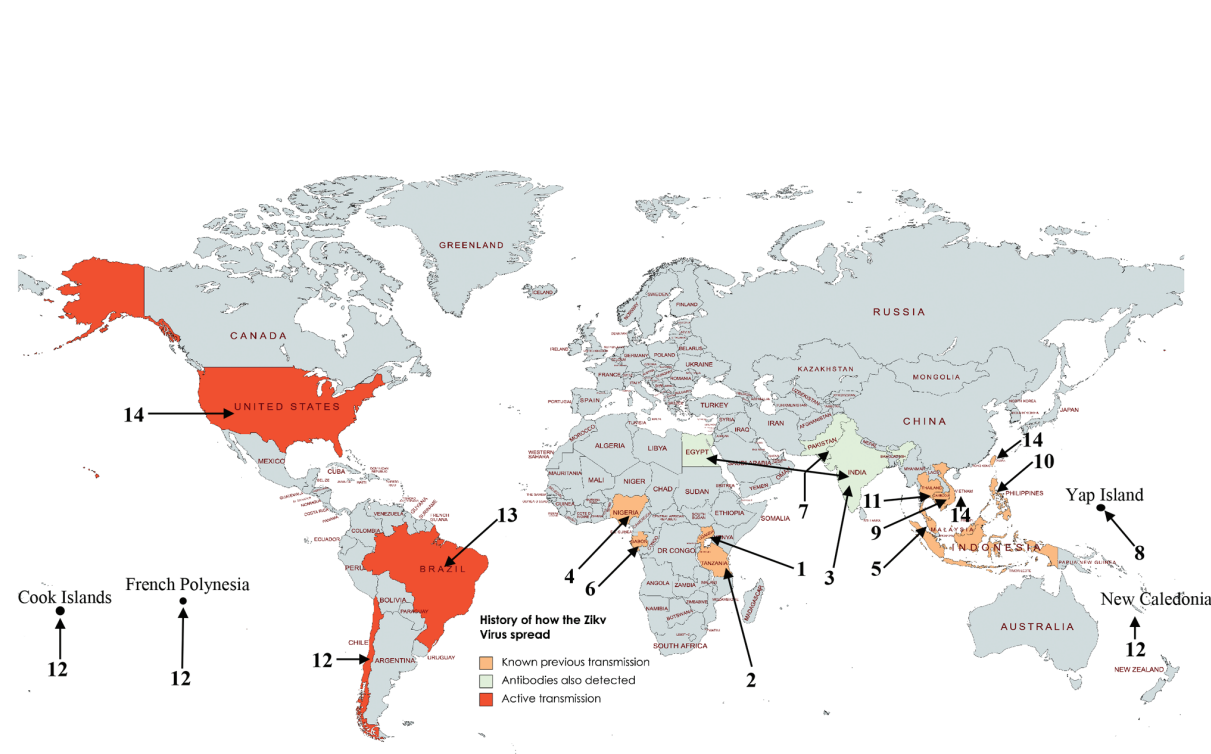

8. 2007: Zika Virus outbreak was reported in Yap Island.

9. 2010: Zika virus is reported in Cambodia. 10. 2012: Zika virus outbreak occurred in Philippines. 11. 2012-2014: Zika virus outbreak occurred in Thailand. 12. 2013-2014: Zika virus outbreaks in four other groups of Pacific islands: French Polynesia, Easter Island, the Cook Islands, and New Caledonia. 13. 2015: Brazilian ministry of Health confirmed the transmission of the virus in Brazil. 14. 2016-2017: Zika virus reported in countries: United States, Taiwan, and Vietnam.

FIGURE 2 | World map showing the timeline of events of ZIKV epidemics. As Zika virus travels from one country to another, the world map is labeled with numbers, years and colors indicating how Zika virus arose and evolved over time. 


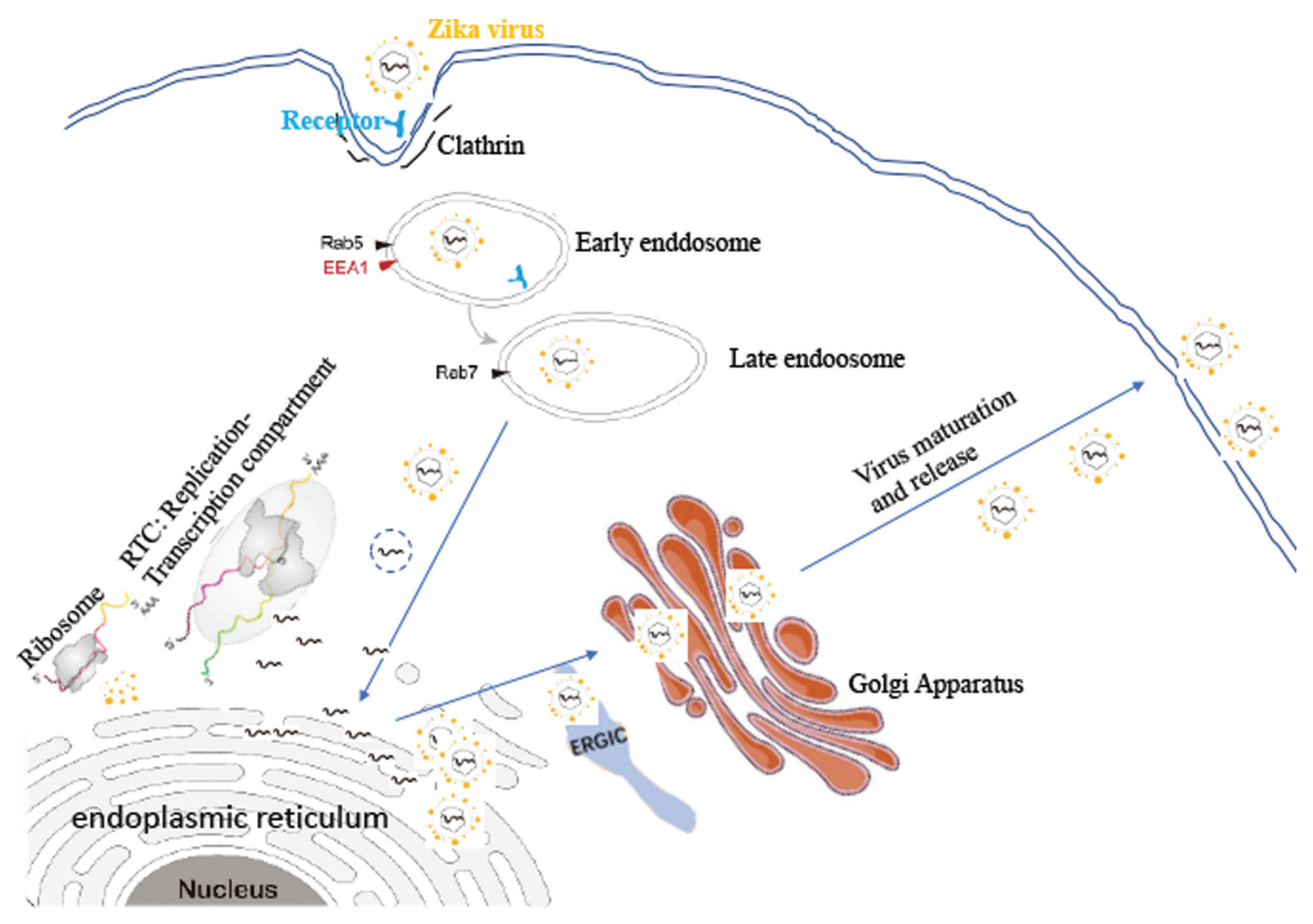

FIGURE 3 | The viral life cycle in host cells.

Afterward, an increase in neonatal microcephaly cases was reported in southeast Brazil [58,59]. ZIKV has been isolated from the amniotic fluid of mothers pregnant with infants with confirmed microcephaly [56,58-60]. ZIKV has also been isolated from the brain of a fetus with congenital central nervous system (CNS) abnormalities [4]. In Brazil, a systematic study has linked ZIKV to microcephaly; the investigators followed patients in Rio de Janeiro, Brazil, and reported the clinical manifestations of acute ZIKV infection in mothers and consequent fetal effects [61]. The study enrolled pregnant women who had rash develop within the prior 5 days. The pregnant women's blood and urine samples were obtained to test for ZIKV through reverse transcriptase-polymerase chain reaction (PCR) assays. The women were prospectively enrolled and followed to collect data on the pregnancy and infant outcomes. A total of 345 women were enrolled from September 2015 through May 2016, among whom 182 women (53\%) tested positive according to ZIKV PCR in the blood, urine or both. The timing of acute ZIKV infection ranged from 6 to 39 weeks of gestation. In ultrasound studies in a total of 153 women, 59 women were found to be positive for ZIKV during pregnancy. The remaining 75 women who were positive for ZIKV declined imaging analysis because either the facility was too far away or they feared knowing whether their child had fetal abnormalities associated with ZIKV infection. The women who tested negative for ZIKV infection still received regular prenatal care. Regarding infant outcomes, 49 of the 117 live-born infants (42\%) were infected with
ZIKV in utero, and the infants during the first month of life showed abnormal findings primarily affecting the CNS. Microcephaly was observed in infants whose mothers were infected with ZIKV in weeks 8, 12, 30 and 38 of gestation. Although only mild clinical symptoms were observed in mothers with ZIKV infection during pregnancy, this finding should not be taken lightly, because ZIKV harms fetuses, causing fetal death, fetal growth restriction and many CNS abnormalities [61].

A review by Wen et al. lists the approaches used during 2016-2017 to investigate ZIKV-caused microcephaly and summarizes the mechanistic information on how ZIKV causes microcephaly [62]. The modeling approaches included 1) two-dimensional (2D) cell culture of NPCs [63]; 2) three-dimensional (3D) culture of NPCs; 3) mouse models and 4) NHP models. First, the 2D studies in human NPCs revealed that ZIKV infection dysregulates cellular gene expression, mitigates NPC growth, induces autophagy or apoptosis, and increases cell death [63-66]. Second, studies using 3D models indicated that ZIKV decreases neuronal-cell-layer thickness and overall volume, attenuates organoid growth, and impairs cortical growth and folding $[12,64,67]$. Moreover, in IFN-deficient mouse models (A129 or AG129), ZIKV has been detected in the placenta and brain, and found to be transmitted to the fetus, thus resulting in CNS neurodegeneration [68-71]. NHPs are clearly the best model for ZIKV infection and pathogenesis. ZIKV infection in Rhesus macaques causes symptoms similar to those in humans, and viral particles are detected in the 
saliva, urine and cerebrospinal fluid. Many studies using the in vitro and in vivo models have demonstrated that ZIKV is directly associated with microcephaly.

Given that ZIKV can affect newborns' health before they even have a chance of living a normal healthy life, further understanding of how ZIKV infection affects cellular physiology is crucial [4]. Microcephaly is believed to be related to abnormal centrosome function [17]. Centrosomes are cellular organelles that serve as the primary microtubuleorganizing centers of animal cells. Centrosomes have roles in mitosis and vesicle migration, polarization and trafficking [17]. Studies have demonstrated that in vitro ZIKV infection alters cellular functions including mitosis, and causes spindle misorientation and increased centrosome numbers [66,72-74]. Greater numbers of centrosomes correlate with microcephaly. A delay in mitosis and an increase in apoptosis can occur when the centrosome number increases [17]. Cells infected with ZIKV have disrupted centrosome organization and mitotic abnormalities, thus leading to altered neural progenitor differentiation [66,72-75]. Our recent studies have also demonstrated that ZIKV infection disrupts the structure and function of pericentral centromere materials [13]. Therefore, when centrosomes and neural progenitor differentiation are affected by ZIKV, microcephaly may develop after cell cycle arrest, increased apoptosis and halted NPC cell differentiation result in abnormal neural cell development.

\section{ZIKV and Guillain-Barré syndrome}

The characteristics of ZIKV include not only microcephaly in neonates but also Guillain-Barré syndrome (GBS) in adults [76,77]. Although a link has been reported between ZIKV and GBS, more research is needed. During the ZIKV outbreak in FP, an unexpectedly high number of GBS cases was observed. In December 2013, the first patient presenting with "Zika-like syndrome" symptoms, including low fever, myalgia, rash and conjunctivitis, was diagnosed with GBS and hospitalized [78]. Patients with ZIKV-associated GBS are mostly men and exhibit neurological symptoms. During the epidemic of ZIKV in Brazil, cases of GBS increased by 20-fold. Collectively, these epidemiological data reinforce the hypothesis of a relationship between ZIKV and GBS. Ocular complications in adults have been reported [79]. The Centers for Disease Control and Prevention is actively investigating the association between ZIKV and GBS. Thus, ZIKV is known to cause congenital neurodevelopmental defects, including microcephaly in children and possibly GBS in adults.

\section{Mechanistic studies of ZIKV pathogenesis in the CNS}

To understand the mechanisms underlying how ZIKV causes microcephaly and other CNS disorders, multiple models have been applied. As described above, ZIKV-associated disorders occur primarily in congenitally infected neonates, as shown in Fig 4A. The in vitro models have included 2D and 3D cell cultures. The animal models have primarily included mouse and NPH models. Primary human NPCs (Fig 4B), hiNSC-derived NPCs, microglial cell lines and human dermal fibroblast cells have been used to investigate the effects of ZIKV on cellular function, growth, death, apoptosis and innate defenses (Fig 4C). Moreover, 3D NPCs, such as hiPSC-derived cerebral organoids, hiPSC-derived forebrain organoids and hiPSC-derived cerebral neutrospheres, have been used to study the viral effects on neural cell differentiation. ZIKV has a wide range of permissive cell types [80], thus supporting its efficient infection and replication. ZIKV infection causes increased cell death, disrupted cell cycle progression, dysregulated gene expression, attenuated human NPC growth and apoptosis [55,63-66,81-83]. ZIKV replicates in primary human neural progenitors and induces cell death, inhibition of the Akt-mTOR pathway, activation of autophagy, centrosomal depletion and mitochondrial sequestration of phospho-TBK1 $[83,84]$. ZIKV preferentially infects NSCs, astrocytes, oligodendrocyte precursor cells and microglia [85]. ZIKV infects NPCs in the VZ, impairs cell cycle progression, activates immune responses [86] and induces antiviral gene expression [86]. AXL mediates ZIKV entry and modulates innate immune responses [52,87]. ZIKV can infect and replicate in primary human trophoblasts [88,89], which resist ZIKV infection and release IFN $\lambda 1$ [89,90]. ZIKV infects and replicates in Hofbauer cells and induces IFN, proinflammatory cytokine and antiviral gene expression [89]. ZIKV infects cells via $\mathrm{AXL}$ and other factors and induces the transcription of TLR3, RIG-I and MDA5. Increased cell death, decreased proliferation, and decreased neuronal-cell-layer thickness and overall cell size have been observed in ZIKV-infected 3D culture models [10-12,64,74].

The first animal models for ZIKV were immunocompromised mice, such as A129 or AG129, which lack IFNI or IFNII responses (Fig 4B). Those studies have revealed how ZIKV is transmitted from mother to fetus. Although wild type (WT) adult mice are important for ZIKV study, they are resistant to ZIKV infection [7,91,92]. The mice used as models for ZIKV studies to date have deficiencies in either the IFN or the IFN receptor, induced either genetically or via antibody treatment [93]. The A129 mouse has genetically knocked out receptors for type I IFN (IFN-alpha and IFN-beta) and hence is not susceptible to IFN-alpha and IFN-beta stimulation, and is vulnerable to ZIKV infection [70]. The AG129 mouse lacks the IFN-alpha, IFN-beta and IFN-gamma receptors $[70,94]$. Another mouse strain with triple knockout of three genes (irf $3^{-/-}$, irf $5^{-/-}$and irf $7^{-/-}$) produces little IFN-alpha and IFN-beta and is also fatally susceptible to ZIKV infection [94]. The importance of IFNalpha/beta signaling in preventing ZIKV infection has also been confirmed with anti-IFN-alpha receptor antibodies. Blockade of the type I IFN response with the anti-IFNaR1 antibody in pregnant WT mice enables ZIKV to cross the placenta and infect the fetus [95]. Beyond IFN-alpha, IFNbeta and IFN-gamma receptors, elevated ZIKV replication has recently been observed in the placenta and fetus when the fetus lacks IFN- $\lambda$ receptor [92]. With these mouse 
A.

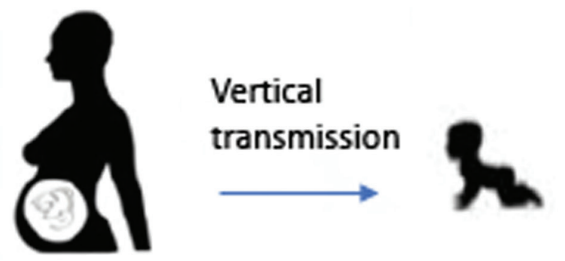

\section{Congenital infection-caused CNS disorders (hearing loss, blindness, intellectual retardedness, microcephaly)}

B.

Models for biological studies
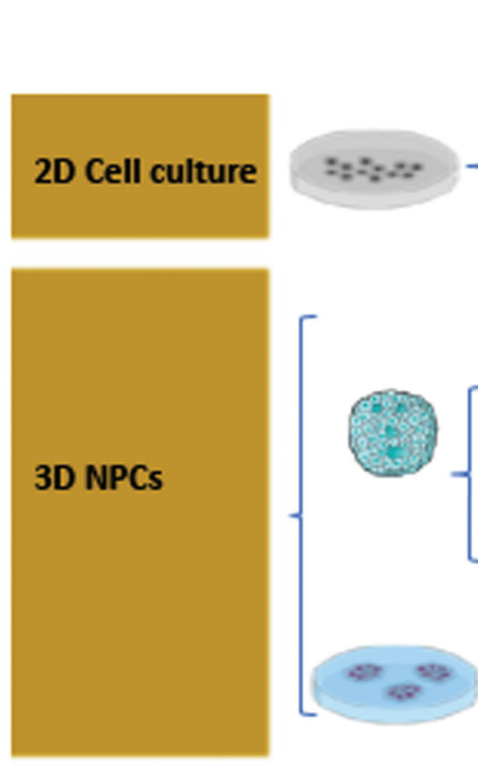

Primary hNPCs
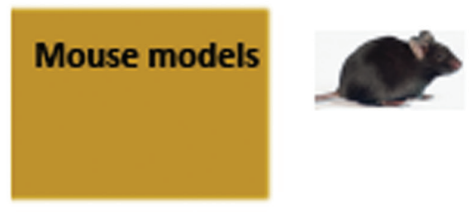

ICR, C57BL/6, A129, AG129, C57BL/6J

Rhesus macaques

\section{Functional effects on cells/animals}

Efficient infection and replication in $\mathrm{hNPC}$, Increased cell death; Disrupted cell cycle progression; Dysregulated gene expression; Apoptosis; Inhibition of the Akt-mTOR pathway; Impaired neurogenesis; Activation of autophagy; Centrosomal depletion and disrupted mitoses; Altered differentiation of primary hNSCs

Activation of immune responses; Induction of antiviral gene expression; AXI mediates ZIKV entry; ZIKV infects and replicates in Hofbauer cells; Induces IFN, proinflanmatory cytokines; Antiviral gene expression; Induces the transcription of TLR3, RIG-I, and MDA5; Decreased neuronal cell layer thickness and overall size.

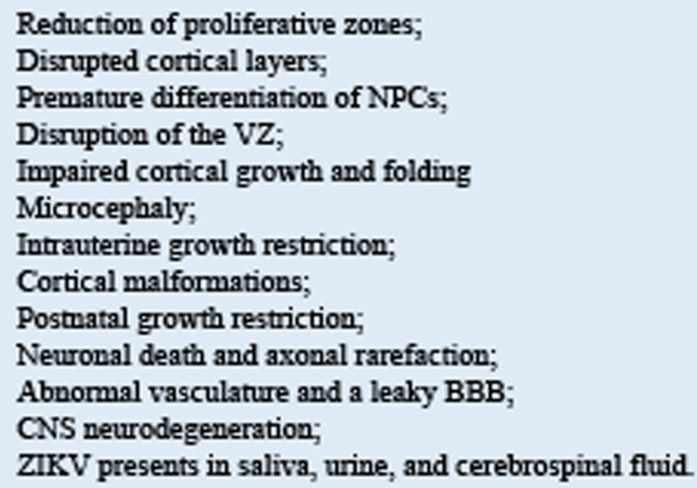

FIGURE 4 | In vitro and in vivo models for investigating ZIKV-associated CNS disorders and outcomes.

models, ZIKV has been found to decrease proliferative zones, disrupt cortical layers, interfere with the differentiation of NPCs, and impair neurogenesis and folding of neural progenitor cells. Studies in other animal models have used NHPs, such as Rhesus macaques, to confirm the information obtained from mouse models. ZIKV has been detected in the brain and found to cause signs of neurologic disease in NHPs. In NHPs, ZIKV is present in the saliva, urine and cerebrospinal fluid, and causes symptoms similar to those in humans [96-98]. The effects of ZIKV infection on cells and animals are summarized in Fig 4C.

\section{ANIMAL MODELS OF ZIKV}

ZIKV has continued to spread worldwide for many years, but ZIKV pathogenesis and its mechanisms are not yet fully understood, as research continues. Using animal models of infection and disease is necessary to provide preliminary understanding of ZIKV pathogenesis and mechanisms that could enable development a vaccine [99]. Animal models are crucial for understanding ZIKV pathogenesis and mechanisms to enable vaccine development.

\section{Small-animal models}

\section{Immunocompetent mouse models}

Animal models of ZIKV infection did not gain traction until the recent ZIKV epidemic. From the first isolation of ZIKV in 1947 until 2015, only three animal-model studies were published, in which researchers tested viral pathogenic potential $[22,100,101]$. This lag in research may be one reason why ZIKV pathogenesis and mechanisms are not yet fully understood. In the first publication of a mouse 
model for ZIKV, the prototype MR766 strain of ZIKV was injected into the skulls of mice and found to cause neurological disease, such as motor weakness and paralysis of the limbs in suckling or adult mice [22]. However, when adult immunocompetent mice were intraperitoneally infected with ZIKV, no sign of disease was observed, thereby indicating that the infection route through the skull is essential to initiate successful infection [99]. Recently, researchers have examined ZIKV infection and disease in non-pregnant and pregnant immunocompetent mice infected with contemporary ZIKV strains [99]. After ZIKV injection, some mice notably showed no clinical disease, and very few or no signs of ZIKV were detected in WT C57BL/6, Swiss Webster, BALB/c and CD-1 mice $[69,70,94,102]$. During these outbreaks, researchers developed animal models of ZIKV infection and pathogenesis by using different strains of ZIKV; similar results have been reported in a 2017 review [93]. ZIKV does not naturally adapt to replicate in immunocompetent mice, because it is missing part of the species-specific immune evasion mechanism; consequently, the use of immunocompetent mice in ZIKV research has been limited. Nevertheless, immunocompetent mice still have important roles in research and have been used to evaluate vaccine immunogenicity and efficacy in protecting against viremia $[93,102]$.

\section{Immunocompromised mouse models}

Although immunocompetent mouse models cannot support ZIKV replication and disease naturally, several groups have examined the possibility of developing ZIKV infection and disease in immunocompromised adult mice. The innate immune system plays a key role in identifying viral infections through the recognition of pathogen-associated molecular patterns (PAMPs) by innate-immune-system receptors called host pattern-recognition receptors (PRRs) [103]. When the PRRs and PAMPS interact, signaling cascades ultimately increase the production of cytokines, including type I interferon (IFN), via the transcription factors NF- $\mathrm{KB}$ and interferon regulatory factors (IRFs) [104]. In animal models, various groups have altered IFN responses, which are important for antiviral defense [99]. The receptors of IFN- $\alpha$ and IFN- $\beta$, downstream signaling molecules and signal transducer and activator of transcription 1 (STAT-1) are crucial in protecting against viral infection $[105,106]$. The IRFs, particularly IRF3 and IRF7 are crucial in ensuring that the type I IFN response follows viral infection [106]. Type II IFN or IFN-gamma communicates through a distinct receptor, IFNGR1, the canonical cytokine in adaptive Th1 immunity, which is required to respond to intracellular pathogens [107]. A129 mice (129S2 Ifnar1tm1Agt) and Ifnar1 ${ }^{-/-} \mathrm{C} 57 \mathrm{BL} / 6$ mice or mice deficient in transcription factors IRF3/5/ $/ 7^{-/-}$ lack the receptor for type I IFN and consequently are vulnerable to both the African and Asian lineages of ZIKV and have high viral doses in the brain $[70,94,95,108,109]$. When these animals are injected with ZIKV, they develop symptoms including hind-limb weakness, paralysis and death. The disease severity in these immunocompromised mice depends on their age: older mice (11 weeks old) are less prone to infection than younger mice ( $3-5$ weeks old) [70,94]. Mice lacking both the type I and type II IFN receptors (AG129, 129/Sv Ifnar1tm1Agt Ifngr1tm1Agt) show greater disease severity after ZIKV infection than their counterpart A129 mice [70,110-112]. Analysis of tissues after ZIKV infection in A129 and AG129 mice has revealed that ZIKV is present primarily in the testes and brain. The presence of ZIKV in the testes is consistent with reports of ZIKV's mode of transmission including sexual transmission. In addition, signal transducer and activator of transcription 2 (Stat2) $)^{-/-}$mice are highly likely to be infected with ZIKV. After injection with ZIKV, Stat2 $2^{-/-}$ mice show neurological symptoms, and ZIKV is found in their CNS, gonads and other visceral organs [113]. Stat $2^{-/-}$mice lack both type 1 and type III IFN signaling. ZIKV infection from an Asian strain in gestation in pregnant Ifnar $1^{-/-} \mathrm{C} 57 \mathrm{BL} / 6$ mice has been found to last from days 6.5 and 7.5, during which some fetal death occurs; survivors of ZIKV infection show uterine problems such as growth restriction and growth impairment [68]. In these experiments, Ifnar ${ }^{-/-}$mice were mated with WT sires, thus resulting in fetuses heterozygous for IFNAR1. Although the fetuses respond to type I IFN, some severe outcomes have been observed, thus implying that a type 1 IFN response in the fetus does not protect the fetus from ZIKV induced injury [68].

Overall, these immunocompromised mouse models have demonstrated ZIKV's ability to cause fetal abnormalities and deterioration of gonadal tissue, and to be sexually transmitted $[35,68,91,93,114,115]$. In addition, these mouse models have been extensively used to understand the pathogenesis and mechanisms to eventually develop a vaccine for ZIKV [93,116-120]. Although these immunocompromised mouse models are helpful for understanding ZIKV's pathogenesis and mechanism, and eventually creating a vaccine, the models have limitations that must be considered in experimental design and data analysis.

\section{Postnatal ZIKV infection in mice}

Recent in vivo studies in mouse models and human case studies have revealed that ZIKV can pass through the placental barrier and infect fetuses, which may die or develop microcephaly or other malformations of the brain [94,112,121]. Most mouse models have been used to study congenital infection of ZIKV; whether ZIKV infection in newborns (a postnatal infection) could cause severe disease remains unknown. The results from our group and others have shown that ZIKV not only replicates in neonatal mice (WT) but also causes their death $[6,71,94,95,122-124]$. Our recent studies [124] have indicated that 1) several strains of WT neonatal mice are susceptible to ZIKV infection via different infection routes, and 2) ZIKV infection causes 100\% mortality of 1 - to 3-day-old mice, 50-70\% mortality of 5- to 7-day-old mice, and no deaths of 14-day-old or older mice. However, how ZIKV infection causes death in neonatal 
mice remains unknown. A neonatal mouse model might be useful to uncover whether and how ZIKV can infect newborns and cause disease. ZIKV infection in neonatal mice has been reported by several groups $[6,71,94,95,122,123]$. Our unpublished data show that ZIKV infection in neonatal mice results in heart diseases accompanied by abnormal EKG and degradation of gap junction protein alpha ( $\mathrm{Cx} 43$, also known as GJA1). The EKG data exhibit 1) extended P-R, suggesting a block of atrioventricular conductance; 2) widened QRS, suggesting an intraventricular conductance block; and 3) S-T elevation, indicating myocardial injury, all of which are characteristic of myocardial infarction [125] resulting from necrosis. We hypothesize that ZIKV infection impairs the function of the neonatal heart and leads to sudden death.

\section{Large-animal models of ZIKV infection Non-human-primate models}

Researchers are also using NHP models for studying ZIKV, because NHPs should aid in understanding the pathogenesis and mechanism of ZIKV and eventual vaccine creation because of their genetic similarities to humans. Because monkeys have close genetic similarity to humans, some researchers are studying Rhesus macaques, which are susceptible to both the African and Asian strains of ZIKV [93,96,126-128]. When Rhesus macaques are infected with ZIKV, they develop viremia $2-6$ days post-infection, and by 10 days, the viremia is undetectable. ZIKV is present in various parts of the body, such as in the organs, urine, saliva and cerebrospinal fluid in some animals $[96,126]$. Interestingly, several tissues of cynomolgus macaques have been found to be infected with ZIKV, including the male reproductive tract, intestines, brain and spinal cord $[129,130]$. Pregnant ZIKV-infected Rhesus macaques develop viremia, which lasts from 30 to 55 days $[96,126,127]$. Subcutaneous injection of an Asian-lineage strain of ZIKV into a pregnant pigtail macaque has been found to decrease brain growth in her offspring $[131,132]$. In the fetal brain, ZIKV infection damages the CNS. ZIKV has been detected in the placenta, fetal brain and liver, and maternal brain, eyes, spleen and liver [132]. ZIKV infection prompts a T-cell response to protect NHPs against ZIKV reinfection and heterologous infection $[96,129]$. Therefore, NHPs are valuable in testing to develop a vaccine and to assess its efficacy before its distribution. In summary, NHP models are crucial in understanding the pathogenesis and mechanism of ZIKV and eventually developing a vaccine, because the DNA of NHPs and humans is highly similar. Although NHP models are excellent for studying ZIKV, they are expensive to maintain and require more space than other models such as small-animal models.

\section{ZIKV DIAGNOSTICS}

Finding the best diagnostic test for detecting ZIKV depends on the stage of the disease, which is divided into two phases: acute and convalescent [133]. During the acute phase, infection occurs during early stages wherein the viruses replicates in the infected cells and causes the host to develop viremia. When the clinical manifestations are complete, an initial response to the infection is mounted, and IgM antibody production increases to fight the virus. This immune response is also part of the acute phase. The convalescent phase is the opposite of the acute phase; it begins during the late stage of infection, when IgG antibodies are more specific in their response to the developing virus. An ideal diagnostic test should have high sensitivity and specificity to correctly identify individuals positive for the virus without detecting those negative for the virus [133]. The diagnostic tests include molecular and serological assays. Molecular assay is mainly used for the detection of genetic variants, whereas serological assays can be used to detect previous circulating virus and measure patient immune response to the virus by detecting antibodies to the virus in the serum [133]. Clinical evaluation alone is not sufficient to truly understand ZIKV diagnosis, because of excessive cross-reactivity with other arboviruses. Therefore, the Centers for Disease Control and Prevention established guidelines for ZIKV diagnosis consisting of a reverse transcriptase reaction assays followed by real-time polymerase chain reaction (RT-PCR), IgM antibody-capture enzyme-linked immunosorbent assay (MAC-ELISA) and plaque reduction neutralization testing (PRNT).

The RT-PCR assay is a reliable diagnostic method but is suitable only when the infection remains in the acute phase, because the viral RNA can still be identified in body fluids [133]. RT-PCR assay sensitivity is important to avoid false-negative results. However, limitations exist, owing to the emergence of variants of ZIKV. As many as ten nucleotide mismatches have been identified between the oligonucleotide sequences reported in published assays and the consensus sequence of the Asian-lineage ZIKV strain. In addition, as many as five mismatches have been found in individual primers or probes, thus potentially limiting the RT-PCR sensitivity, given the genetic variability of the Asian-lineage strain of ZIKV [134,135]. In summary, continual research is necessary to detect new ZIKV variants and update the primer and probe sequences to avoid confusion; such an update would improve the detection sensitivity.

MAC-ELISA, a serologic test, qualitatively detects antibodies in the serum or cerebrospinal fluid. One drawback is that MAC-ELISA results can be complex to understand, owing to possible non-specific antibody reactivity.Therefore, tests that are positive, ambiguous or inconclusive should be confirmed with PRNT-serological testing that can use a specific antibody to neutralize a virus by preventing plaque formation in a cell monolayer. PRNT is currently considered the "gold standard" in differentiating flavivirus serological diagnosis, because of its high specificity. Although this assay performs well, it is expensive, requiring highly specialized laboratories that have the proper equipment to perform cell culture and crucially have permission to work with the active virus. In addition, training in safe use and handling of this assay is necessary, because it is complex to perform; 
moreover, the results usually are not available for 5-10 days $[135,136]$.

Several commercial serological tests are available, and the most impressive are those from Euroimmun AG (Germany) and InBios (USA). The first available serological commercial test for ZIKV detection was the Euroimmun assay, which has been extensively evaluated in the literature [137-140]. The anti-ZIKV IgM/IgG/IgA ELISA is based on an ELISA using the NS1 protein of ZIKV to detect IgM, IgG and IgA in serum samples. According to Huzly et al. [137], this test has shown high specificity in testing of various samples from patients with previous exposure to flavivirus infections. To understand which tests are best, the tests must be compared. L'Huillier et al. [138] have conducted a comparative study using Euroimmun IgM and IgG ELISAs and MAC-ELISA, and subsequent PRNT to confirm whether the results were positive or inconclusive. Notably, the Euroimmun's combined $\mathrm{IgG} / \mathrm{IgM}$ test had good specificity (95\%), better than that of the MAC-ELISA. However, the sensitivity of this test was far lower than that of the MAC-ELISA (39.5\%).

The InBios assay, also referred to as the ZIKV Detect ${ }^{\mathrm{TM}}$ 2.0 IgM Capture ELISA Kit, is for in vitro diagnostic use only. The ZIKV Detect ${ }^{\mathrm{TM}} 2.0$ IgM Capture ELISA Kit is used for qualitative detection of ZIKV IgM antibodies in human sera. This assay was the first commercial serology kit to receive FDA Marketing Authorization in the USA, on May 23, 2019. The ZIKV Detect ${ }^{\mathrm{TM}} 2.0$ IgM Capture ELISA Kit has recently replaced the ZIKV Detect ${ }^{\mathrm{TM}}$ IgM Capture ELISA Kit, and numerous significant changes were made from the original.According to Basile et al. [141], the average sensitivity increased from $90.4 \%$ to $92.5 \%$ with the ZIKV Detect $^{\mathrm{TM}} 2.0 \mathrm{IgM}$ Capture ELISA Kit, and the specificity increased from 79.5\% to $97.4 \%$ - an important $17.9 \%$ difference. In addition, the accuracy of the updated kit was $89 \%$, compared with $63.9 \%$, with a significant $25.1 \%$ difference from the original kit. The agreement among laboratories increased from $79.5 \%$ to $97.4 \%$, a significant $17.5 \%$ difference. In summary, these data have shown that the ZIKV Detect $^{\text {TM }} 2.0$ IgM Capture ELISA Kit is a successful in vitro diagnostic test that should be further investigated, given its potential to decrease the number of PRNT confirmation tests. Overall, all these assays have great potential for routine diagnostic laboratories if they pass each stage of a systematic clinical evaluation.

\section{CONCLUSIONS AND PERSPECTIVES}

Although the ZIKV epidemic has put the world on notice, clear understanding of ZIKV pathogenesis, prevention and treatment has been lacking. In the near future, such understanding will be essential to elucidate ZIKV pathogenesis and enable the development of clear prevention and treatment plans. The mechanisms of how ZIKV infection causes congenital microcephaly and GBS require further investigation. Animal models will continue to be an essential resource for researchers studying ZIKV pathogenesis and progression. When ZIKV pathogenesis is understood, creating a vaccine will be a logical next step, as with any other viruses. As they develop ZIKV vaccine, researchers may need to examine the ZIKV family and genus to build on prior successful experiences in combatting those viruses. After a ZIKV vaccine is developed, researchers must test the vaccine on the animal models to ensure that it is effective before it is approved to be distributed to the general population.

Some critical questions concerning ZIKV still remain. First, only $5 \%$ of the neonates born to ZIKV-infected mothers during pregnancy develop microcephaly. What are the non-viral factors that enable ZIKV to cause neurodegeneration? Second, although the Asian strain has been demonstrated to be more pathogenic than the African strain, both strains exhibit similar effects on cells. A larger number of strains should be applied in infection studies in both cells (2D or $3 \mathrm{D}$ cultures) and animals to assess the pathogenic effects of ZIKV and obtain more definitive answers. Third, although ZIKV infection is widely accepted to induce impaired growth and NPC death, which may be the major pathway underlying ZIKV-associated microcephaly, ZIKVmediated defects in mitosis may play a role, given that we and others have consistently found that ZIKV causes degradation of pericentral materials 1 (PCM1) or structural damage to centrosomes. These experimental results still lack support from animal studies. In addition, whether ZIKV infection is associated with functional failures of systems other than the CNS should be investigated. For example, can ZIKV infection affect heart development and cause heart diseases? Finally, the ZIKV epidemic has been over for many years, and ZIKV infections are now rarely reported. Should it be expected to recur? A long-term prospective investigation in previously infected patients should now be conducted to determine whether ZIKV has long-term effects on humans.

\section{ACKNOWLEDGEMENTS}

This study was supported by funding from NIH/NIAID SC1AI112785 (Q.T.), the National Institute on Minority Health/Health Disparities of the National Institutes of Health under Award Number G12MD007597 (Q.T.) and the Howard University Leadership Alliance Summer program (D.V.).

\section{COMPETING INTERESTS}

The authors have no other competing interests to disclose.

\section{REFERENCES}

1. Bollati M, Alvarez K, Assenberg R, Baronti C, Canard B, Cook $S$, et al. Structure and functionality in flavivirus NS-proteins: perspectives for drug design. Antiviral Res. 2010;87(2):125-148.

2. Gatherer D, Kohl A. Zika virus: a previously slow pandemic spreads rapidly through the Americas. J Gen Virol. 2016;97(2):269-273.

3. McDougall WM, Perreira JM, Hung HF, Vertii $A$, Xiaofei E, Zimmerman $W$, et al. Viral Infection or IFN-alpha alters mitotic spindle orientation by modulating pericentrin levels. iscience. 2019;12:270-279.

4. Mlakar J, Korva M, Tul N, Popovic M, Poljsak-Prijatelj M, Mraz J, et al. Zika virus associated with microcephaly. N Engl J Med. 2016;374(10):951-958. 
5. Network. NBDP. Major birth defects data from population based birth defects surveillance programs in the United States. Birth Defects Research (Part A): Clinical and Molecular Teratology. 2013;97:S1-S172.

6. Zhang F, Wang HJ, Wang Q, Liu ZY, Yuan L, Huang XY, et al. American strain of Zika virus causes more severe microcephaly than an old Asian strain in neonatal mice. EBioMedicine. 2017;25:95-105.

7. Li C, Xu D, Ye Q, Hong S, Jiang Y, Liu X, et al. Zika virus disrupts neural progenitor development and leads to microcephaly in mice. Cell Stem Cell. 2016;19(5):672.

8. Wang S, Hong S, Deng YQ, Ye Q, Zhao LZ, Zhang FC, et al. Transfer of convalescent serum to pregnant mice prevents Zika virus infection and microcephaly in offspring. Cell Res. 2017;27(1):158-160.

9. Shao Q, Herrlinger S, Yang SL, Lai F, Moore JM, Brindley MA, et al. Zika virus infection disrupts neurovascular development and results in postnatal microcephaly with brain damage. Development. 2016;143(22):4127-4136.

10. Qian X, Nguyen HN, Song MM, Hadiono C, Ogden SC, Hammack $C$, et al. Brain-region-specific organoids using mini-bioreactors for modeling ZIKV exposure. Cell. 2016;165:1238-1254.

11. Garcez PP, Loiola EC, Madeiro da Costa R, Higa LM, Trindade $P$, Delvecchio $R$, et al. Zika virus impairs growth in human neurospheres and brain organoids. Science. 2016;352(6287):816-818.

12. Dang J, Tiwari SK, Lichinchi G, Qin Y, Patil VS, Eroshkin AM, et al. Zika virus depletes neural progenitors in human cerebral organoids through activation of the innate immune receptor TLR3. Cell Stem Cell. 2016;19(2):258-265.

13. Wen F, Armstrong N, Hou W, Cruz-Cosme R, Obwolo LA, Ishizuka K, et al. Zika virus increases mind bomb 1 levels, causing degradation of pericentriolar material 1 (PCM1) and dispersion of PCM1-containing granules from the centrosome. J Biol Chem. 2019;294(49):18742-18755.

14. Johansson MA, Mier-y-Teran-Romero L, Reefhuis J, Gilboa SM, Hills SL. Zika and the risk of microcephaly. N Engl J Med. 2016;375(1):1-4.

15. Barreto ML, Barral-Netto M, Stabeli R, Almeida-Filho N, Vasconcelos PF, Teixeira M, et al. Zika virus and microcephaly in Brazil: a scientific agenda. Lancet. 2016;387(10022):919-921.

16. Macnamara FN. Zika virus: a report on three cases of human infection during an epidemic of jaundice in Nigeria. Trans R Soc Trop Med Hyg. 1954;48(2):139-145.

17. Chang C, Ortiz K, Ansari A, Gershwin ME. The Zika outbreak of the 21st century. J Autoimmun. 2016;68:1-13.

18. Marcondes CB, Ximenes Mde F. Zika virus in Brazil and the danger of infestation by Aedes (Stegomyia) mosquitoes. Rev Soc Bras Med Trop. 2016;49(1):4-10.

19. Li MI, Wong PS, Ng LC, Tan CH. Oral susceptibility of Singapore Aedes (Stegomyia) aegypti (Linnaeus) to Zika virus. PLoS Negl Trop Dis. 2012;6(8):e1792.

20. Plourde AR, Bloch EM. A literature review of Zika virus. Emerg Infect Dis. 2016;22(7):1185-1192.

21. Dick GW, Kitchen SF, Haddow AJ. Zika virus. I. Isolations and serological specificity. Trans R Soc Trop Med Hyg. 1952;46(5):509-520.

22. Dick GW. Zika virus. II. Pathogenicity and physical properties. Trans R Soc Trop Med Hyg. 1952;46(5):521-534.

23. Akoua-Koffi C, Diarrassouba S, Benie VB, Ngbichi JM, Bozoua $\mathrm{T}$, Bosson $\mathrm{A}$, et al. [Investigation surrounding a fatal case of yellow fever in cote d'Ivoire in 1999]. Bull Soc Pathol Exot. 2001;94(3):227-230.

24. Berthet N, Nakoune E, Kamgang B, Selekon B, DescorpsDeclere S, Gessain A, et al. Molecular characterization of three Zika flaviviruses obtained from sylvatic mosquitoes in the Central African Republic. Vector Borne Zoonotic Dis. 2014;14(12):862-865.
25. Diallo D, Sall AA, Diagne CT, Faye O, Faye O, Ba Y, et al. Zika virus emergence in mosquitoes in southeastern senegal, 2011. PLoS One. 2014;9(10):e109442.

26. Fagbami AH. Zika virus infections in Nigeria: virological and seroepidemiological investigations in Oyo State. J Hyg (Lond) 1979;83(2):213-219.

27. Grard G, Caron M, Mombo IM, Nkoghe D, Mboui Ondo S, Jiolle D, et al. Zika virus in Gabon (Central Africa)-2007: a new threat from Aedes albopictus? PLoS Negl Trop Dis. 2014;8(2):e2681.

28. Haddow AJ, Williams MC, Woodall JP, Simpson DI, Goma LK. Twelve isolations of Zika virus from aedes (stegomyia) africanus (theobald) taken in and above a uganda forest. Bull World Health Organ. 1964;31:57-69.

29. Marchette NJ, Garcia R, Rudnick A. Isolation of Zika virus from Aedes aegypti mosquitoes in Malaysia. Am J Trop Med Hyg. 1969;18(3):411-415.

30. McCrae AW, Kirya BG. Yellow fever and Zika virus epizootics and enzootics in Uganda. Trans R Soc Trop Med Hyg. 1982;76(4):552-562.

31. Souza-Neto JA, Powell JR, Bonizzoni M. Aedes aegypti vector competence studies: a review. Infect Genet Evol. 2019;67:191-209.

32. Sakkas H, Bozidis P, Giannakopoulos X, Sofikitis N, Papadopoulou C. An update on sexual transmission of Zika virus. Pathogens. 2018;7(3):66.

33. Foy BD, Kobylinski KC, Chilson Foy JL, Blitvich BJ, Travassos da Rosa A, Haddow AD, et al. Probable non-vector-borne transmission of Zika virus, Colorado, USA. Emerg Infect Dis. 2011;17(5):880-882.

34. Moreira J, Peixoto TM, Siqueira AM, Lamas CC. Sexually acquired Zika virus: a systematic review. Clin Microbiol Infect. 2017;23(5):296-305.

35. Tang WW, Young MP, Mamidi A, Regla-Nava JA, Kim K, Shresta S. A mouse model of Zika virus sexual transmission and vaginal viral replication. Cell Rep. 2016;17(12):3091-3098.

36. Aquaculture Genomics G, Breeding W, Abdelrahman H, ElHady M, Alcivar-Warren A, Allen S, et al. Aquaculture genomics, genetics and breeding in the United States: current status, challenges, and priorities for future research. BMC Genomics. 2017;18(1):191.

37. Teixeira FME, Pietrobon AJ, Oliveira LM, Oliveira L, Sato MN Maternal-fetal interplay in Zika virus infection and adverse perinatal outcomes. Front Immunol. 2020;11:175.

38. Guedes GR, Coutinho RZ, Marteleto L, Pereira WHS, Duarte $D$. Why social perception matters during disease outbreaks: looking at how individuals understand the Zika virus by self-reported history of infection. Cad Saude Publica. 2018;34(9):e00139718.

39. Harris-Sagaribay $L$, Chambers $C D$, Perrotta K, Polen $K D$, Honein MA, Wasternack E. A model partnership for communication and dissemination of scientific recommendations for pregnant women during the emergency response to the Zika virus outbreak: MotherToBaby and the centers for disease control and prevention. Birth Defects Res. 2020;112(18):1545-1550.

40. Pang $W$, Lin $Y L$, Xin $R$, Chen $X X$, Lu $Y$, Zheng $C B$, et al. Zika virus transmission via breast milk in suckling mice. Clin Microbiol Infect. 2021;27(3):469 e1-469 e7.

41. In: nd, editor. Guideline: Infant Feeding in Areas of Zika Virus Transmission. Geneva: World Health Organization; 2021.

42. Guideline: Infant Feeding in Areas of Zika Virus Transmission. Geneva: World Health Organization; 2016.

43. Hayes EB. Zika virus outside Africa. Emerg Infect Dis. 2009;15(9):1347-1350.

44. Song BH, Yun SI, Woolley M, Lee YM. Zika virus: history, epidemiology, transmission, and clinical presentation. J Neuroimmunol. 2017;308:50-64. 
45. Haddow AD, Schuh AJ, Yasuda CY, Kasper MR, Heang V, Huy R, et al. Genetic characterization of Zika virus strains: geographic expansion of the Asian lineage. PLoS Negl Trop Dis. 2012;6(2):e1477

46. Pettersson JH, Bohlin J, Dupont-Rouzeyrol M, Brynildsrud OB, Alfsnes K, Cao-Lormeau VM, et al. Re-visiting the evolution, dispersal and epidemiology of Zika virus in Asia. Emerg Microbes Infect. 2018;7(1):79.

47. Olson JG, Ksiazek TG, Suhandiman, Triwibowo. Zika virus, a cause of fever in central Java, Indonesia. Trans R Soc Trop Med Hyg. 1981;75(3):389-393.

48. Baronti C, Piorkowski G, Charrel RN, Boubis L, Leparc-Goffart I, de Lamballerie X. Complete coding sequence of Zika virus from a French polynesia outbreak in 2013. Genome Announc. 2014;2(3):e00500-14.

49. Faye O, Freire CC, lamarino A, Faye O, de Oliveira JV, Diallo M, et al. Molecular evolution of Zika virus during its emergence in the $20^{\text {th }}$ century. PLoS Negl Trop Dis. 2014;8(1):e2636.

50. Duffy MR, Chen TH, Hancock WT, Powers AM, Kool $J \mathrm{~L}$, Lanciotti RS, et al. Zika virus outbreak on Yap Island, Federated States of Micronesia. N Engl J Med. 2009;360(24):2536-2543.

51. Hussain A, Ali F, Latiwesh OB, Hussain S. A comprehensive review of the manifestations and pathogenesis of Zika virus in neonates and adults. Cureus. 2018;10(9):e3290.

52. Meertens L, Labeau A, Dejarnac O, Cipriani S, Sinigaglia L, Bonnet-Madin L, et al. Axl mediates ZIKA virus entry in human glial cells and modulates innate immune responses. Cell Rep. 2017;18(2):324-333.

53. Nobrega GM, Samogim AP, Parise PL, Venceslau EM, Guida JPS Japecanga RR, et al. TAM and TIM receptors mRNA expression in Zika virus infected placentas. Placenta. 2020;101:204-207.

54. Li F, Wang PR, Qu LB, Yi CH, Zhang FC, Tang XP, et al. AXL is not essential for Zika virus infection in the mouse brain. Emerg Microbes Infect. 2017;6(3):e16.

55. Wells MF, Salick MR, Wiskow O, Ho DJ, Worringer KA, Ihry RJ, et al. Genetic ablation of AXL does not protect human neural progenitor cells and cerebral organoids from Zika virus infection. Cell Stem Cell. 2016;19(6):703-708.

56. Oliveira Melo AS, Malinger G, Ximenes R, Szejnfeld PO, Alves Sampaio S, Bispo de Filippis AM. Zika virus intrauterine infection causes fetal brain abnormality and microcephaly: tip of the iceberg? Ultrasound Obstet Gynecol. 2016;47(1):6-7.

57. Ventura CV, Maia M, Bravo-Filho V, Gois AL, Belfort R, Jr. Zika virus in Brazil and macular atrophy in a child with microcephaly. Lancet. 2016;387(10015):228.

58. Schuler-Faccini L, Sanseverino M, Vianna F, da Silva AA, Larrandaburu $M$, Marcolongo-Pereira $C$, et al. Zika virus: a new human teratogen? Implications for women of reproductive age. Clin Pharmacol Ther. 2016;100(1):28-30.

59. Schuler-Faccini L, Ribeiro EM, Feitosa IM, Horovitz DD, Cavalcanti DP, Pessoa A, et al. Brazilian medical genetics societyzika embryopathy task F. Possible association between Zika virus infection and microcephaly - Brazil, 2015. MMWR Morb Mortal Wkly Rep. 2016;65(3):59-62

60. Calvet G, Aguiar RS, Melo AS, Sampaio SA, de Filippis I, Fabri $A$, et al. Detection and sequencing of Zika virus from amniotic fluid of fetuses with microcephaly in Brazil: a case study. Lancet Infect Dis. 2016;16(6):653-660.

61. Brasil P, Pereira JP, Jr., Moreira ME, Ribeiro Nogueira RM, Damasceno $\mathrm{L}$, Wakimoto $\mathrm{M}$, et al. Zika virus infection in pregnant women in Rio de Janeiro. N Engl J Med. 2016;375(24):2321-2334.

62. Wen Z, Song H, Ming GL. How does Zika virus cause microcephaly? Genes Dev. 2017;31(9):849-861.

63. Tang H, Hammack C, Ogden SC, Wen Z, Qian X, Li Y, et al. Zika virus infects human cortical neural progenitors and attenuates their growth. Cell Stem Cell. 2016;18(5):587-590.
64. Cugola FR, Fernandes IR, Russo FB, Freitas BC, Dias $J \mathrm{~L}$, Guimaraes KP, et al. The Brazilian Zika virus strain causes birth defects in experimental models. Nature. 2016;534(7606):267-271.

65. Ghouzzi VE, Bianchi FT, Molineris I, Mounce BC, Berto GE, Rak $M$, et al. ZIKA virus elicits P53 activation and genotoxic stress in human neural progenitors similar to mutations involved in severe forms of genetic microcephaly. Cell Death Dis. 2016;7(10):e2440.

66. Souza BS, Sampaio GL, Pereira CS, Campos GS, Sardi SI, Freitas $L A$, et al. Zika virus infection induces mitosis abnormalities and apoptotic cell death of human neural progenitor cells. Sci Rep. 2016;6:39775.

67. Li Y, Muffat J, Omer A, Bosch I, Lancaster MA, Sur M, et al. Induction of expansion and folding in human cerebral organoids. Cell Stem Cell. 2017;20(3):385-396 e3.

68. Miner JJ, Cao B, Govero J, Smith AM, Fernandez E, $\mathrm{Cabrera} \mathrm{OH}$, et al. Zika virus infection during pregnancy in mice causes placental damage and fetal demise. Cell. 2016;165(5):1081-1091.

69. Rossi SL, Vasilakis N. Modeling Zika virus infection in mice. Cell Stem Cell. 2016;19(1):4-6.

70. Rossi SL, Tesh RB, Azar SR, Muruato AE, Hanley KA, Auguste AJ, et al. Characterization of a novel murine model to study Zika virus. Am J Trop Med Hyg. 2016;94(6):1362-1369.

71. Manangeeswaran $M$, Ireland DD, Verthelyi D. Zika (PRVABC59) infection is associated with T cell infiltration and neurodegeneration in CNS of immunocompetent neonatal C57bl/6 mice. PLoS Pathog. 2016;12(11):e1006004.

72. Wolf B, Diop F, Ferraris P, Wichit S, Busso C, Misse D, et al. Zika virus causes supernumerary foci with centriolar proteins and impaired spindle positioning. Open Biol. 2017;7(1):160231.

73. Ferraris P, Cochet M, Hamel R, Gladwyn-Ng I, Alfano C, Diop F, et al. Zika virus differentially infects human neural progenitor cells according to their state of differentiation and dysregulates neurogenesis through the Notch pathway. Emerg Microbes Infect. 2019;8(1):1003-1016.

74. Gabriel E, Ramani A, Karow U, Gottardo M, Natarajan K, Gooi LM, et al. Recent Zika virus isolates induce premature differentiation of neural progenitors in human brain organoids. Cell Stem Cell. 2017;20(3):397-406 e5.

75. Kesari AS, Heintz VJ, Poudyal S, Miller AS, Kuhn RJ, LaCount DJ. Zika virus NS5 localizes at centrosomes during cell division. Virology. 2020;541:52-62.

76. White MK, Wollebo HS, David Beckham J, Tyler KL, Khalili K. Zika virus: an emergent neuropathological agent. Ann Neurol. 2016;80(4):479-489.

77. Brasil P, Sequeira PC, Freitas AD, Zogbi HE, Calvet GA, de Souza RV, et al. Guillain-barre syndrome associated with Zika virus infection. Lancet. 2016;387(10026):1482.

78. Oehler E, Watrin L, Larre P, Leparc-Goffart I, Lastere S, Valour $F$, et al. Zika virus infection complicated by Guillain-Barre syndrome-case report, French Polynesia, December 2013. Euro Surveill. 2014;19(9):20720.

79. Fontes BM. Zika virus-related hypertensive iridocyclitis. Arq Bras Oftalmol. 2016;79(1):63.

80. Hou W, Armstrong N, Obwolo LA, Thomas M, Pang X, Jones $K S$, et al. Determination of the cell permissiveness spectrum, mode of RNA replication, and RNA-protein interaction of Zika virus. BMC Infect Dis. 2017;17(1):239.

81. Zhang Y. Biology of the Mi-2/NuRD complex in slac (stemness, longevity/ageing, and cancer). Gene Regul Syst Bio. 2011;5:1-26.

82. Hanners NW, Eitson JL, Usui N, Richardson RB, Wexler EM, Konopka G, et al. Western Zika virus in human fetal neural progenitors persists long term with partial cytopathic and limited immunogenic effects. Cell Rep. 2016;15(11):2315-2322. 
83. Liang Q, Luo Z, Zeng J, Chen W, Foo SS, Lee SA, et al. Zika virus NS4A and NS4B proteins deregulate Akt-mTOR signaling in human fetal neural stem cells to inhibit neurogenesis and induce autophagy. Cell Stem Cell. 2016;19(5):663-671.

84. Onorati M, Li Z, Liu F, Sousa AM, Nakagawa N, Li M, et al. Zika virus disrupts phospho-TBK1 localization and mitosis in human neuroepithelial stem cells and radial glia. Cell Rep. 2016;16(10):2576-2592.

85. Retallack H, Di Lullo E, Arias C, Knopp KA, Laurie MT, Sandoval-Espinosa $C$, et al. Zika virus cell tropism in the developing human brain and inhibition by azithromycin. Proc Natl Acad Sci U S A. 2016;113(50):14408-14413.

86. Bayless NL, Greenberg RS, Swigut T, Wysocka J, Blish CA. Zika virus infection induces cranial neural crest cells to produce cytokines at levels detrimental for neurogenesis. Cell Host Microbe. 2016;20(4):423-428.

87. Hamel R, Ferraris P, Wichit S, Diop F, Talignani L, Pompon $J$, et al. Zika virus strains differentially induce early antiviral responses in primary human astrocytes. Infect Genet Evol. 2017;49:134-137.

88. Aagaard KM, Lahon A, Suter MA, Arya RP, Seferovic MD, Vogt $M B$, et al. Primary human placental trophoblasts are permissive for Zika Virus (ZIKV) replication. Sci Rep. 2017;7:41389.

89. Quicke KM, Bowen JR, Johnson EL, McDonald CE, Ma $\mathrm{H}, \mathrm{O}$ 'Neal JT, et al. Zika virus infects human placental macrophages. Cell Host Microbe. 2016;20(1):83-90.

90. Bayer A, Lennemann NJ, Ouyang Y, Bramley JC, Morosky S, Marques ET, et al. Type III interferons produced by human placental trophoblasts confer protection against Zika virus infection. Cell Host Microbe. 2016;19(5):705-712.

91. Ma W, Li S, Ma S, Jia L, Zhang F, Zhang Y, et al. Zika virus causes testis damage and leads to male infertility in mice. Cell. 2016;167(6):1511-1524 e10.

92. Jagger BW, Miner JJ, Cao B, Arora N, Smith AM, Kovacs A, et al. Gestational stage and IFN-lambda signaling regulate ZIKV infection in utero. Cell Host Microbe. 2017;22(3):366-376 e3.

93. Morrison TE, Diamond MS. Animal models of Zika virus infection, pathogenesis, and immunity. J Virol. 2017;91(8):9-17.

94. Lazear HM, Govero J, Smith AM, Platt DJ, Fernandez E, Miner JJ, et al. A mouse model of Zika virus pathogenesis. Cell Host Microbe. 2016;19(5):720-730.

95. Miner JJ, Sene A, Richner JM, Smith AM, Santeford A, Ban $\mathrm{N}$, et al. Zika virus infection in mice causes panuveitis with shedding of virus in tears. Cell Rep. 2016;16(12):3208-3218.

96. Dudley DM, Aliota MT, Mohr EL, Weiler AM, Lehrer-Brey G, Weisgrau KL, et al. A rhesus macaque model of Asian-lineage Zika virus infection. Nat Commun. 2016;7:12204.

97. Abbink P, Larocca RA, De La Barrera RA, Bricault CA, Moseley $E T$, Boyd $M$, et al. Protective efficacy of multiple vaccine platforms against Zika virus challenge in rhesus monkeys. Science. 2016:353(6304):1129-1132.

98. Hirsch AJ, Smith JL, Haese NN, Broeckel RM, Parkins CJ, Kreklywich $C$, et al. Zika virus infection of rhesus macaques leads to viral persistence in multiple tissues. PLoS Pathog. 2017;13(3):e1006219.

99. Krause KK, Azouz F, Shin OS, Kumar M. Understanding the pathogenesis of Zika virus infection using animal models. Immune Netw. 2017;17(5):287-297.

100. Bell TM, Field EJ, Narang HK. Zika virus infection of the central nervous system of mice. Arch Gesamte Virusforsch. 1971;35(2):183-193.

101. Way JH, Bowen ET, Platt GS. Comparative studies of some African arboviruses in cell culture and in mice. J Gen Virol. 1976;30(1):123-130.

102. Larocca RA, Abbink P, Peron JP, Zanotto PM, lampietro MJ, Badamchi-Zadeh $A$, et al. Vaccine protection against Zika virus from Brazil. Nature. 2016;536(7617):474-478.
103. Medzhitov R. Toll-like receptors and innate immunity. Nat Rev Immunol. 2001;1(2):135-145.

104. Honda K, Taniguchi T. IRFs: master regulators of signalling by Toll-like receptors and cytosolic pattern-recognition receptors. Nat Rev Immunol. 2006;6(9):644-658.

105. Haller $O$, Kochs $G$, Weber $F$. The interferon response circuit: induction and suppression by pathogenic viruses. Virology. 2006;344(1):119-130.

106. Suthar MS, Diamond MS, Gale M, Jr. West Nile virus infection and immunity. Nat Rev Microbiol. 2013;11(2):115-128.

107. Schoenborn JR, Wilson CB. Regulation of interferon-gamma during innate and adaptive immune responses. Adv Immunol. 2007;96:41-101.

108. Dowall SD, Graham VA, Rayner E, Atkinson B, Hall G, Watson RJ, et al. A susceptible mouse model for Zika virus infection. PLoS Negl Trop Dis. 2016;10(5):e0004658.

109. Li H, Saucedo-Cuevas L, Regla-Nava JA, Chai G, Sheets N, Tang $W$, et al. Zika virus infects neural progenitors in the adult mouse brain and alters proliferation. Cell Stem Cell. 2016;19(5):593-598.

110. Zmurko J, Marques RE, Schols D, Verbeken E, Kaptein SJ, Neyts J. The viral polymerase inhibitor 7-deaza-2'-Cmethyladenosine is a potent inhibitor of in vitro Zika virus replication and delays disease progression in a robust mouse infection model. PLoS Negl Trop Dis. 2016;10(5):e0004695.

111. Julander JG, Siddharthan V, Evans J, Taylor R, Tolbert K, Apuli $C$, et al. Efficacy of the broad-spectrum antiviral compound BCX4430 against Zika virus in cell culture and in a mouse model. Antiviral Res. 2017;137:14-22.

112. Aliota MT, Caine EA, Walker EC, Larkin KE, Camacho E, Osorio JE. Characterization of lethal Zika virus infection in AG129 mice. PLoS Negl Trop Dis. 2016;10(4):e0004682.

113. Tripathi S, Balasubramaniam VR, Brown JA, Mena I, Grant A, Bardina SV, et al. A novel Zika virus mouse model reveals strain specific differences in virus pathogenesis and host inflammatory immune responses. PLoS Pathog. 2017;13(3):e1006258.

114. Govero J, Esakky P, Scheaffer SM, Fernandez E, Drury A, Platt DJ, et al. Zika virus infection damages the testes in mice. Nature. 2016;540(7633):438-442

115. Yockey LJ, Varela L, Rakib T, Khoury-Hanold W, Fink SL, Stutz $B$, et al. Vaginal exposure to Zika virus during pregnancy leads to fetal brain infection. Cell. 2016;166(5):1247-1256 e4.

116. Bullard-Feibelman KM, Govero J, Zhu Z, Salazar V, Veselinovic M, Diamond MS, et al. The FDA-approved drug sofosbuvir inhibits Zika virus infection. Antiviral Res. 2017;137:134-140.

117. Deng YQ, Zhang NN, Li CF, Tian M, Hao JN, Xie XP, et al. Adenosine analog NITD008 is a potent inhibitor of Zika virus. Open Forum Infect Dis. 2016;3(4):ofw175.

118. Zhao H, Fernandez E, Dowd KA, Speer SD, Platt DJ, Gorman MJ, et al. Structural basis of Zika virus-specific antibody protection. Cell. 2016;166(4):1016-1027

119. Swanstrom JA, Plante JA, Plante KS, Young EF, McGowan E, Gallichotte EN, et al. Dengue virus envelope dimer epitope monoclonal antibodies isolated from dengue patients are protective against Zika Virus. mBio. 2016;7(4):e01123-16.

120. Sapparapu G, Fernandez E, Kose N, Bin C, Fox JM, Bombardi RG, et al. Neutralizing human antibodies prevent Zika virus replication and fetal disease in mice. Nature. 2016;540(7633):443-447.

121. Hickman HD, Pierson TC. Zika in the brain: new models shed light on viral infection. Trends Mol Med. 2016;22(8):639-641.

122. Fernandes NC, Nogueira JS, Ressio RA, Cirqueira CS, Kimura $L M$, Fernandes $K R$, et al. Experimental Zika virus infection induces spinal cord injury and encephalitis in newborn Swiss mice. Exp Toxicol Pathol. 2017;69(2):63-71.

123. van den Pol AN, Mao G, Yang Y, Ornaghi S, Davis JN. Zika virus targeting in the developing brain. J Neurosci. 2017;37(8):2161-2175. 
124. Li S, Armstrong N, Zhao H, Hou W, Liu J, Chen C, et al. Zika virus fatally infects wild type neonatal mice and replicates in central nervous system. Viruses. 2018;10(1):49.

125. Mythili S, Malathi N. Diagnostic markers of acute myocardial infarction. Biomed Rep. 2015;3(6):743-748.

126. Li XF, Dong HL, Huang $X Y$, Qiu YF, Wang HJ, Deng $Y Q$, et al. Characterization of a 2016 clinical isolate of Zika virus in nonhuman primates. EBioMedicine. 2016;12:170-177.

127. Nguyen SM, Antony KM, Dudley DM, Kohn S, Simmons HA, Wolfe B, et al. Highly efficient maternal-fetal Zika virus transmission in pregnant rhesus macaques. PLoS Pathog. 2017;13(5):e1006378.

128. Aliota MT, Dudley DM, Newman CM, Mohr EL, Gellerup DD, Breitbach ME, et al. Heterologous protection against Asian Zika virus challenge in rhesus macaques. PLoS Negl Trop Dis. 2016;10(12):e0005168.

129. Osuna CE, Lim SY, Deleage C, Griffin BD, Stein D, Schroeder LT, et al. Zika viral dynamics and shedding in rhesus and cynomolgus macaques. Nat Med. 2016;22(12):1448-1455.

130. Koide F, Goebel S, Snyder B, Walters KB, Gast A, Hagelin $K$, et al. Development of a Zika virus infection model in cynomolgus macaques. Front Microbiol. 2016;7:2028.

131. Driggers RW, Ho CY, Korhonen EM, Kuivanen S, Jaaskelainen AJ, Smura T, et al. Zika virus infection with prolonged maternal viremia and fetal brain abnormalities. N Engl J Med. 2016;374(22):2142-2151.

132. Adams Waldorf KM, Stencel-Baerenwald JE, Kapur RP, Studholme C, Boldenow E, Vornhagen J, et al. Fetal brain lesions after subcutaneous inoculation of Zika virus in a pregnant nonhuman primate. Nat Med. 2016;22(11):1256-1259.

133. Silva IBB, da Silva AS, Cunha MS, Cabral AD, de Oliveira KCA, Gaspari E, et al. Zika virus serological diagnosis: commercial tests and monoclonal antibodies as tools. J Venom Anim Toxins Incl Trop Dis. 2020;26:e20200019.

134. Corman VM, Rasche A, Baronti C, Aldabbagh S, Cadar D, Reusken CB, et al. Assay optimization for molecular detection of Zika virus. Bull World Health Organ. 2016;94(12):880-892.

135. Shi W, Zhang Z, Ling C, Carr MJ, Tong Y, Gao GF. Increasing genetic diversity of Zika virus in the Latin American outbreak. Emerg Microbes Infect. 2016;5:e68.

136. Roehrig JT, Hombach J, Barrett AD. Guidelines for plaquereduction neutralization testing of human antibodies to dengue viruses. Viral Immunol. 2008;21(2):123-132.

137. Huzly D, Hanselmann I, Schmidt-Chanasit J, Panning M. High specificity of a novel Zika virus ELISA in European patients after exposure to different flaviviruses. Euro Surveill. 2016;21(16).

138. L'Huillier AG, Hamid-Allie A, Kristjanson E, Papageorgiou $L$, Hung S, Wong CF, et al. Evaluation of euroimmun AntiZika virus IgM and IgG enzyme-linked immunosorbent assays for Zika virus serologic testing. J Clin Microbiol. 2017:55(8):2462-2471.

139. Kadkhoda K, Gretchen A, Racano A. Evaluation of a commercially available Zika virus IgM ELISA: specificity in focus. Diagn Microbiol Infect Dis. 2017;88(3):233-235.

140. Steinhagen K, Probst C, Radzimski C, Schmidt-Chanasit J, Emmerich $P$, van Esbroeck $M$, et al. Serodiagnosis of Zika virus (ZIKV) infections by a novel NS1-based ELISA devoid of cross-reactivity with dengue virus antibodies: a multicohort study of assay performance, 2015 to 2016 . Euro Surveill. 2016;21(50):30426

141. Basile AJ, Ao J, Horiuchi K, Semenova V, Steward-Clark E, Schiffer J. Performance of InBios ZIKV Detect $2.0 \mathrm{lgM}$ Capture ELISA in two reference laboratories compared to the original ZIKV Detect IgM Capture ELISA. J Virol Methods. 2019;271:113671.

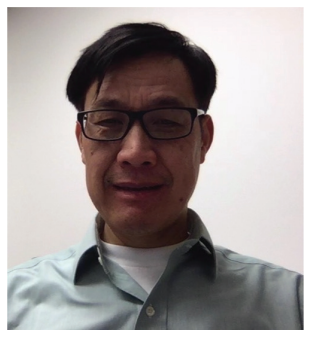

Qiyi Tang (Ph.D.) is a tenured Professor in the Department of Microbiology at the Howard University (HU) College of Medicine. He was trained as a virologist; he has been investigating viruses (herpesviruses, flaviviruses and coronaviruses) for more than 25 years and has authored more than 80 peer-reviewed publications. He serves as the Chairperson of Institutional Biosafety Committee at HU (since 2016) and the Cluster co-leader of Infectious and Immune Diseases (IID) in RTRN (RCMI Translational Research Network) in the USA (since 2015). His group and research have been supported by funding from the NIH, American Cancer Society (ACS), Charles and Mary Latham Fund and American Heart association (AHA). He is a member of the American Society for Microbiology and American Society for Biochemistry and Molecular Biology. He was awarded an award for outstanding faculty researcher of the year (2018) by the Howard University College of Medicine and was the first researcher in Puerto Rico to receive an ACS Scholar grant, San Juan, PR (2009). 